\section{Pollen Appearance and In Vitro Germination Varies for Five Strains of Female Hemp Masculinized Using Silver Thiosulfate}

\author{
Jessica DiMatteo, Lauren Kurtz, and Jessica D. Lubell-Brand \\ Department of Plant Science and Landscape Architecture, University of \\ Connecticut, Storrs, CT 06269-4067
}

Additional index words. Cannabis sativa, feminized seed, foliar sprays

\begin{abstract}
Genetically female seed is sought for cannabidiol (CBD) hemp production because CBD is extracted from the flowers of female hemp plants. The production of all female seed requires masculinization of female plants to produce genetically female pollen that reliably generates female seed. Of the five female hemp genotypes that we masculinized using foliar sprays of silver thiosulfate (Abacus, Cherry Wine, Mountain Mango, Youngsim10, Wife), all genotypes produced fewer large and more irregular or misshapen pollen grains than genetically male plants. The masculinized female genotypes Wife and Cherry Wine produced pollen with germination rates similar to those of the male genotype Kentucky Sunshine. Female hemp genotypes vary in their ability to produce usable pollen that disperses well, is easily collected, and germinates as well as pollen from genetically male hemp plants.
\end{abstract}

Hemp is an annual dioecious species with separate male (XY) and female (XX) plants (Moliterni et al., 2004). Dioecious hemp seed will generate $\approx 50 \%$ male and $50 \%$ female plants (Schaffner, 1921). Female plants are preferred over males for CBD hemp production because female inflorescences accumulate significantly greater cannabinoid content than male inflorescences (Small, 2015). Monoecious plants, which have both male and female flowers, occur occasionally in hemp, and cultivars have been selected for use in the production of industrial hemp fiber and grain. Male and monoecious plants are problematic for $\mathrm{CBD}$ production because of their pollen, which is produced in copious quantities because hemp is a wind-pollinated species (Small and Naraine, 2016). A single male hemp flower can produce hundreds of thousands of pollen grains (Faegri et al., 1989), and hemp pollen can travel long distances by wind (Clarke, 1977).

Although female plants produce greater CBD content than male plants, pollination and subsequent fertilization of female plants lead to seed development, which significantly reduces the $\mathrm{CBD}$ content and, thus, the $\mathrm{CBD}$ yield, of female plants (Meier and Mediavilla, 1998). Therefore, CBD hemp growers must be vigilant when scouting for and removing male or monoecious plants from production fields before the plants release

Received for publication 3 Jan. 2020. Accepted for publication 6 Feb. 2020.

Published online 6 March 2020.

J.D.L.-B. is the corresponding author. E-mail: Jessica.lubell@uconn.edu.

This is an open access article distributed under the CC BY-NC-ND license (https://creativecommons. org/licenses/by-nc-nd/4.0/). pollen (DeDecker, 2019). Scouting and removing males are highly labor-intensive for growers and result in the loss of $\approx 50 \%$ of harvestable land area per production cycle.

In an effort to eliminate male plants in production, growers can use feminized hemp seed, which contains only female embryos (Soler et al., 2017). However, feminized hemp seed is currently difficult to source and prohibitively expensive for many growers (Lee, 2019). Feminized seed is more labor-intensive to produce than nonfeminized seed because it requires the masculinization (induction of male flowers) of female plants. Male flowers induced on genetically female plants will produce pollen grains that contain only $\mathrm{X}$ gametes that, when crossed with eggs from female plants, result in all-female seed (Mohan Ram and Sett, 1982). Female plants can be masculinized by treatment with silver nitrate or silver thiosulfate (STS). Lubell and Brand (2018) demonstrated that foliar sprays of STS at 0.3 to $3 \mathrm{~mm}$ concentrations are effective for inducing male flowers on female plants. They noted that pollen output for masculinized female plants may be reduced compared with pollen output from genetically male plants. We have observed that some female hemp strains make better pollen parents than others following masculinization with STS. The objective of this study was to evaluate differences in germination of pollen from five masculinized female hemp genotypes.

\section{Materials and Methods}

In vitro pollen germination was evaluated for five masculinized female hemp genotypes, Abacus, Cherry Wine, Mountain Mango, Wife, and Youngsim10, and two male hemp genotypes, Kentucky Sunshine and Youngsim10. Plants were grown in a greenhouse with set points of $21{ }^{\circ} \mathrm{C} / 17{ }^{\circ} \mathrm{C}$ day/night. They were well-established in 3-gallon containers and between 1 and $1.5 \mathrm{~m}$ tall, depending on the strain when the flowering stage was initiated. Plants were potted in a peatmoss-based grower mix (ProMix BX; Premier Tech Horticulture, Quakertown, PA) and top-dressed with controlled-release fertilizer (Osmocote Plus $15 \mathrm{~N}-3.9 \mathrm{P}-10 \mathrm{~K}$ 5- to 6-month formulation; Everris NA, Dublin, $\mathrm{OH}$ ) at $64 \mathrm{~g} /$ container. During the vegetative stage, plants received a soluble fertilizer (Peters 20N-8.7P-16.6K; Scotts, Marysville, $\mathrm{OH}$ ) providing $100 \mathrm{ppm}$ nitrogen at every irrigation as needed. Beginning on 26 Sept. 2019, plants were provided short-day conditions of $12 \mathrm{~h}$ using a blackout curtain to initiate the flowering stage. Silver thiosulfate solution at a concentration of $3 \mathrm{~mm}$ was prepared according to Lubell and Brand (2018). Female plants were sprayed to runoff ( $\approx 400 \mathrm{~mL} /$ plant) on three occasions, $7 \mathrm{~d}$ apart, on 26 Sept., 3 Oct., and 10 Oct. 2019. During the flowering stage, plants received a soluble fertilizer (Peters 15N-12.9P-12.5K; Scotts) providing $100 \mathrm{ppm}$ nitrogen at every irrigation (8 L/day).

Pollen grains were collected in 2-mL centrifuge tubes from male plants on 14 Oct. 2019 and from masculinized female plants on 21 Oct. 2019, except for Abacus, which was collected on 28 Oct. 2019. Immediately after collection, pollen was spread on petri dishes containing a gelled medium using a soft bristled brush. The germination medium, described by Zottini et al. (1997), was composed of $17 \%$ sucrose, 30 $\mathrm{mg} \cdot \mathrm{L}^{-1} \mathrm{Ca}\left(\mathrm{NO}_{3}\right)_{2}, 100 \mathrm{mg} \cdot \mathrm{L}^{-1} \mathrm{H}_{3} \mathrm{BO}_{3}$, and $0.7 \%$ agar, with $\mathrm{pH}$ adjusted to 6.4 . Three petri dishes were prepared per genotype. Petri dishes with pollen were maintained for $18 \mathrm{~h}$ at $24^{\circ} \mathrm{C}$ in a growth chamber with a $16-\mathrm{h}$ photoperiod $(25$ umol $\left.\cdot \mathrm{m}^{-2} \cdot \mathrm{s}^{-1}\right)$. Pollen grains were visualized using a compound microscope (MicrophotFXA; Nikon Instruments, Melville, NY) and microscopy camera (Infinity3; Teledyne Lumenera, Ottawa, ON). For each petri dish, up to 200 pollen grains for male plants and 200 to 700 pollen grains for masculinized female plants were scored for germination. Pollen grains were counted as germinated if any organized tip was observed emerging from the pollen wall. Nongerminated spherical pollen grains were counted as large if their diameter was larger than $35 \mu$ and small if their diameter was

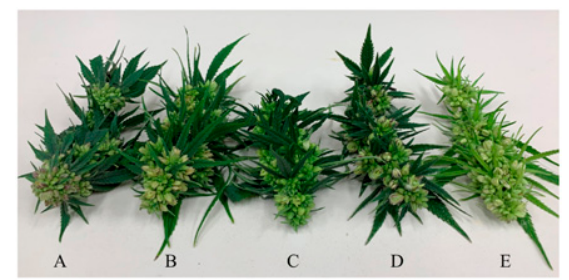

Fig. 1. Terminal inflorescences consisting of male flowers for masculinized female genotypes (A) Abacus, (B) Cherry Wine, (C) Mountain Mango, (D) Wife, and (E) Youngsim10. 
Table 1. Percent of pollen grains germinated, of large and small diameter, and of irregular shape for five masculinized female strains and two male strains of hemp.

\begin{tabular}{lcccc}
\hline & \multicolumn{4}{c}{ Percent of pollen grains } \\
\cline { 2 - 5 } Hemp genotypes & Germinated & Large & Small & Irregular \\
\hline Masculinized female & $0 \mathrm{~d}^{\mathrm{z}}$ & $0 \mathrm{~d}$ & $17 \mathrm{e}$ & $83 \mathrm{a}$ \\
$\quad$ Abacus & $5 \mathrm{~cd}$ & $12 \mathrm{bc}$ & $46 \mathrm{ab}$ & $37 \mathrm{~b}$ \\
$\quad$ Cherry Wine & $4 \mathrm{~d}$ & $9 \mathrm{~cd}$ & $48 \mathrm{a}$ & $38 \mathrm{~b}$ \\
Mountain Mango & $13 \mathrm{~b}$ & $18 \mathrm{~b}$ & $24 \mathrm{de}$ & $44 \mathrm{~b}$ \\
Wife & $2 \mathrm{~d}$ & $3 \mathrm{~cd}$ & $45 \mathrm{abc}$ & $50 \mathrm{~b}$ \\
$\quad$ Youngsim10 & $10 \mathrm{bc}$ & $57 \mathrm{a}$ & $33 \mathrm{bcd}$ & $0 \mathrm{c}$ \\
Male & $19 \mathrm{a}$ & $49 \mathrm{a}$ & $32 \mathrm{~cd}$ & $0 \mathrm{c}$ \\
$\quad$ Kentucky Sunshine & &
\end{tabular}

${ }^{\mathrm{z}}$ Mean separation within columns indicated by different letters according to Fisher's least significant difference at $P \leq 0.05$.
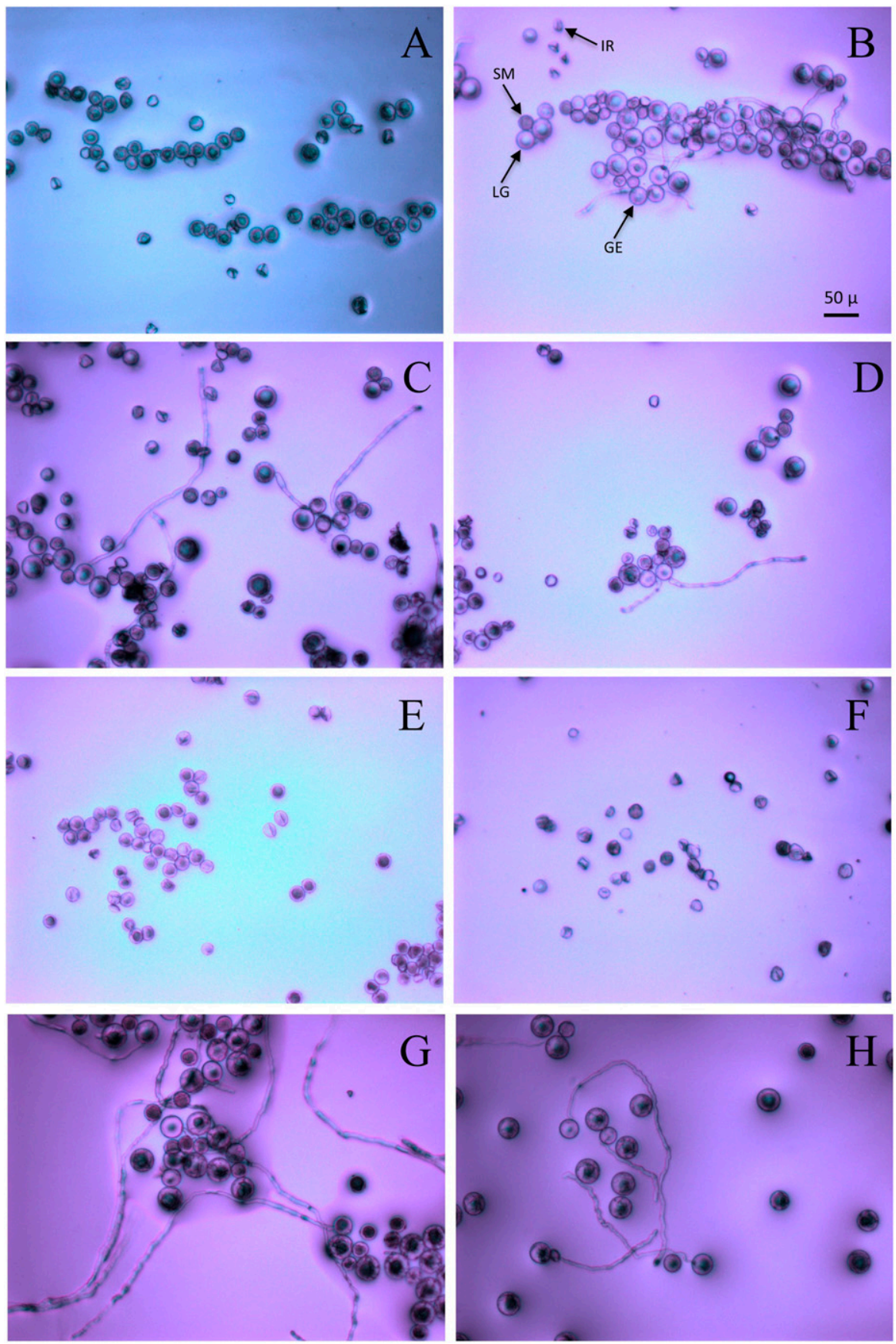

Fig. 2. Freshly collected pollen of masculinized female Wife (A) and 18-hr germinated pollen of masculinized female Wife (B), Cherry Wine (C), Mountain Mango (D), Youngsim10 (E), and Abacus $(\mathbf{F})$, and male Wife $(\mathbf{G})$ and Kentucky sunshine $(\mathbf{H}) . \mathrm{SM}=$ small pollen grain; $\mathrm{LG}=$ large pollen grain; $\mathrm{IR}=$ irregular pollen grain; $\mathrm{GE}=$ germinated pollen grain . smaller than $34 \mu$. The pollen grain diameter was measured for the longest axis using ImageJ (National Institutes of Health, Bethesda, MD). Nonspherical irregular pollen grains were also counted. Data were subjected to an analysis of variance (PROC ANOVA) and mean separation using Fisher's least significant difference test $(P \leq 0.05)$ using SAS software (version 9.2; SAS Institute, Cary, NC).

\section{Results}

All five female genotypes produced male flower buds following treatment with STS. Figure 1 shows terminal inflorescences with male flowers for the five masculinized female genotypes. Flowers on male genotypes began opening and releasing pollen $18 \mathrm{~d}$ after shortday conditions were initiated. Male flowers on all masculinized female genotypes, except Abacus, required $25 \mathrm{~d}$ of short-day conditions before opening. Nearly all flowers on male genotypes opened and released pollen; however, many flowers on masculinized female genotypes did not open, and few flowers opened on Abacus.

Of the five masculinized female genotypes, Wife produced the most visible pollen, which was similar in consistency to pollen from male genotypes. Mountain Mango and Youngsim 10 also produced visible pollen. Cherry Wine flowers did not produce visible pollen as consistently as the other masculinized genotypes, and Abacus did not produce visible pollen. Wife, Mountain Mango, and Youngsim 10 pollen was easy to collect in centrifuge tubes for storage or use in hand pollinations.

Masculinized genotypes Wife and Cherry Wine had pollen germination rates similar to those of genetically male Kentucky Sunshine (Table 1). Wife had the greatest pollen germination percent compared with the other four masculinized female genotypes. Plants produced large-diameter (average $40 \mu$ ) and small-diameter [average $26 \mu ; P=0.0001$ $(\mathrm{n}=30)$ ] pollen grains (Fig. 2). Male genotypes produced significantly more large pollen grains than did masculinized female genotypes (Table 1). All masculinized female genotypes produced a significant number of irregular or misshapen pollen grains (Fig. 2; Table 1), whereas male strains produced none. Abacus produced the greatest percent of irregular pollen grains at $83 \%$ (Table 1). No pollen germination was observed for Abacus.

\section{Discussion}

We observed two different pollen grain sizes, large and small. The difference in pollen grain size could indicate that large grains had undergone microspore mitosis I, which can result in increased grain diameter, and that small grains did not (McCormick, 1993). Irregular or misshapen pollen grains were commonly observed for masculinized female genotypes. Irregular pollen grains could be the result of many things, including abnormal meiosis, improper exine formation, and problems with the tapetal cells (Baghali et al., 2011; Small, 1972). The pollen germination 
rates we observed were less than those reported for hemp by Zottini et al. (1997) using the same germination media. This contrast may be attributable to differences in genotype and growing conditions. Zottini et al. (1997) evaluated pollen germination for the fiber variety Carmagnola, which was grown outdoors in the field. Our pollen germination rates for CBD hemp are similar to those reported for five cultivars of tea hybrid rose (Voyiatzi, 1995).

Overall, those interested in masculinizing female plants to produce all female pollen should generally expect to see lower production of usable pollen than is found with genetically male plants. Pollen output from masculinized females can range from complete failure of some genotypes to other genotypes that yield usable pollen, which is comparable to that from a genetic male. For example, female Abacus did not produce obvious viable pollen, but Wife produced pollen that was essentially equivalent to male pollen because it could be collected and had similar germination percentage. Production of viable pollen from female Cherry Wine, Mountain Mango, and Youngsim10 plants was intermediate. Masculinized female plants can be expected to produce fewer large pollen grains and more misshapen pollen grains than male plants. Pollen from masculinized plants will not disperse as well, will be more challenging to collect in bulk, and may not germinate as well as pollen from genetically male plants.

\section{Literature Cited}

Baghali, Z., A. Majd, A. Chehregani, Z. Pourpak, S. Ayerian, and M. Vatanchian. 2011. Cytotoxic effect of benzo(a)pyrene on development and protein pattern of sunflower pollen grains. Toxicol. Environ. Chem. 93:665-677.

Clarke, R.C. 1977. The botany and ecology of Cannabis. Pods Press, Ben Lomond, CA.

DeDecker, J. 2019. Weighing the risk of cannabis cross-pollination. Michigan State University Extension. 6 Nov. 2019. <https://www.canr.msu. edu/news/weighing-the-risk-of-cannabis-crosspollination>.

Faegri, K., J. Iverson, P.E. Kaland, and K. Krzywinski. 1989. Textbook of pollen analysis, 4th ed. Wiley, New York, NY.

Lee, V. 2019. Projections: U.S. leads in global hemp cultivation. Cannabis Business Times. 31 Oct. 2019. <http://magazine.cannabisbusinesstimes.com/article/october-2019/projectionsus-leads-in-global-hemp-cultivation.aspx>.

Lubell, J.D. and M.H. Brand. 2018. Foliar sprays of silver thiosulfate produce male flowers on female hemp plants. HortTechnology 28:1-5.

McCormick, S. 1993. Male gametophyte development. Plant Cell 5:1265-1275.

Meier, C. and V. Mediavilla. 1998. Factors influencing the yield and the quality of hemp (Cannabis sativa L.) essential oil. J. Intl. Hemp Assoc. 5:16-20.
Mohan Ram, H.Y. and R. Sett. 1982. Induction of fertile male flowers in genetically female Cannabis sativa plants by silver nitrate and silver thiosulphate anionic complex. Theor. Appl. Genet. 62:369-375.

Moliterni, V.M.C., L. Cattivelli, P. Ranalli, and G. Mandolino. 2004. The sexual differentiation of Cannabis sativa L.: A morphological and molecular study. Euphytica 140:95-106.

Small, E. 2015. Evolution and classification of Cannabis sativa (marijuana, hemp) in relation to human utilization. Bot. Rev. 81:189-294.

Small, E. 1972. Interfertility and chromosomal uniformity in Cannabis. Can. J. Bot. 50:1947-1949.

Small, E. and S.G.U. Naraine. 2016. Expansion of female sex organs in response to prolonged virginity in Cannabis sativa (marijuana). Genet. Resources Crop Evol. 63:339-348.

Soler, S., P. Gramazio, M.R. Figas, S. Vilanova, E. Rosa, E.R. Llosa, D. Borras, M. Plazas, and J. Prohens. 2017. Genetic structure of Cannabis sativa var. indica cultivars based on genomic SSR (gSSR) markers: Implications for breeding and germplasm management. Ind. Crops Prod. 104:171-178.

Schaffner, J.H. 1921. Influence of environment on sexual expression in hemp. Bot. Gaz. 71:197219.

Voyiatzi, C.I. 1995. An assessment of the in vitro germination capacity of pollen grains of five tea hybrid rose cultivars. Euphytica 83:199-204.

Zottini, M., G. Mandolino, and P. Ranalli. 1997. Effects of $\gamma$-ray treatment on Cannabis sativa pollen viability. Plant Cell Tissue Organ Cult. 47:189-194. 